\title{
Gastric outlet obstruction due to impacted gallstone
}
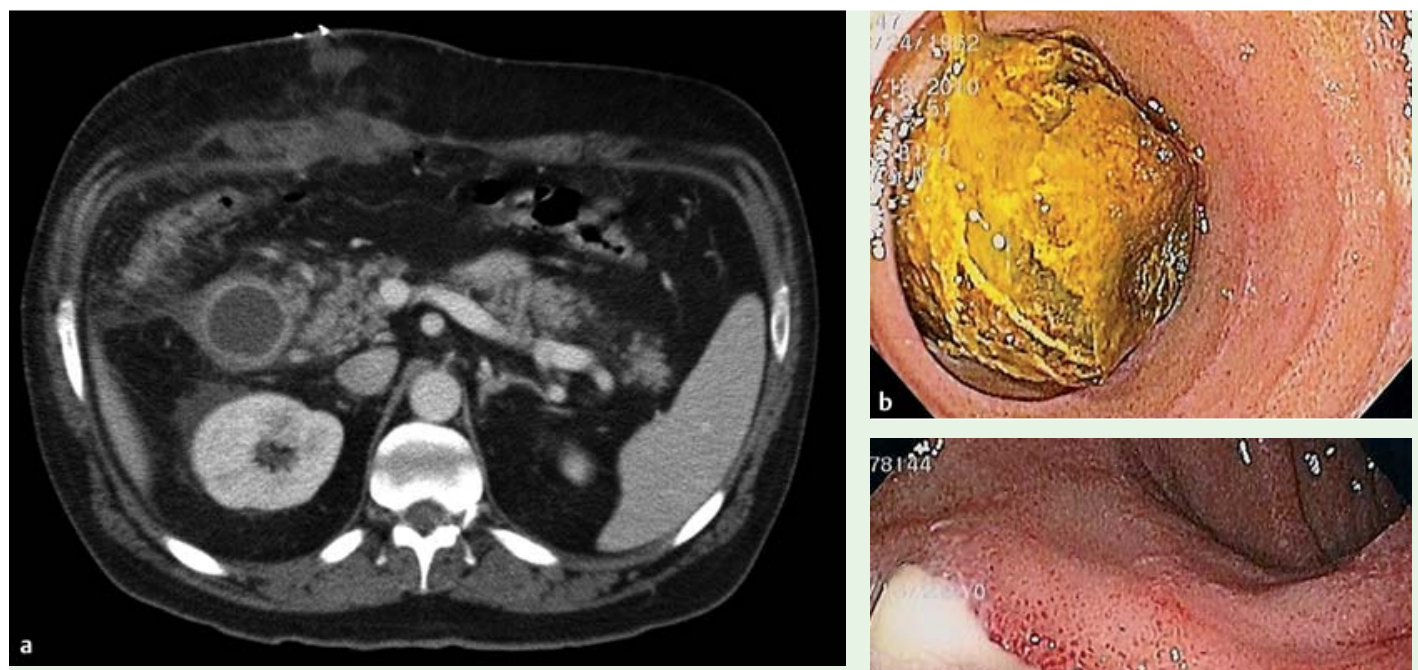

Fig. 1 Images from patient with gastric outlet obstruction due to impacted gallstone. a Computed tomography image demonstrating duodenal obstruction. b Endoscopic view of impacted gallstone in duodenal apex. c Cholecystenteric fistula noted in the duodenal

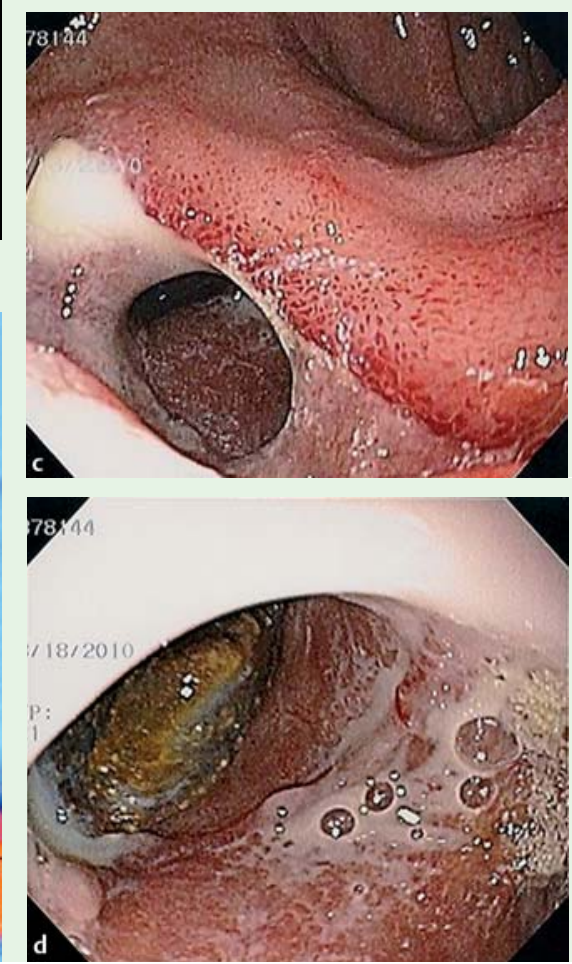
bulb. d Endoscopic view into the gallbladder with additional large gallstone noted.

e Large gallstone removed during surgical exploration.

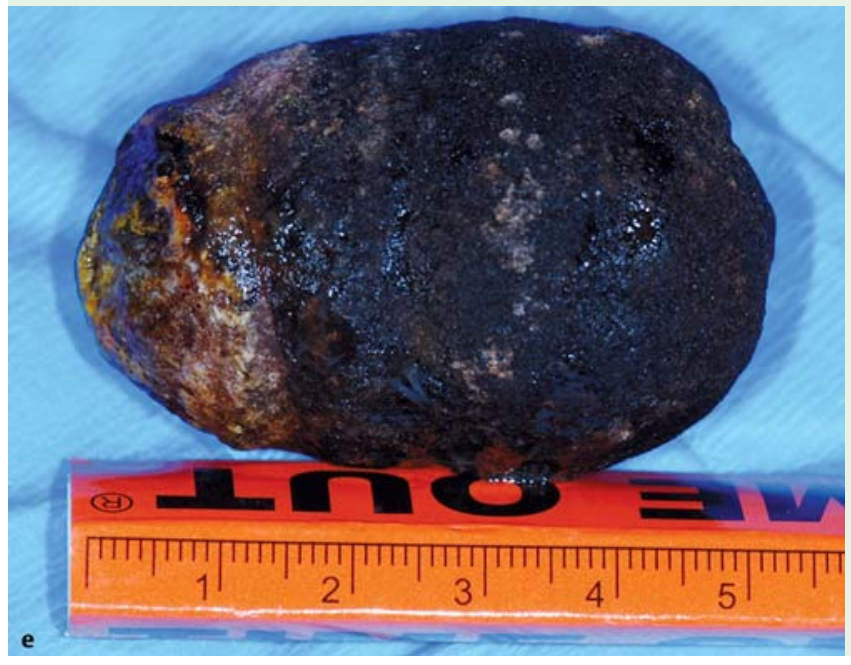

A 47-year-old male with cholelithiasis presented with acute abdominal pain, nausea, and vomiting. Computed tomography (CT) scan showed gangrenous cholecystitis. Cholecystectomy was attempted but aborted due to gallbladder inflammation with complex omental encasement and adherence to the gastroduodenum. Several days later, the patient had recurrence of similar symptoms. A repeat CT scan demonstrated a laminated calcified structure within the duodenum $(3.6 \times 3.9 \mathrm{~cm})$, with proximal distension of the duodenal bulb and gastric antrum consistent with gastric outlet obstruction ( $\bullet$ Fig. 1 a).

Esophagogastroduodenoscopy confirmed a large gallstone impacted within the duodenal apex ( $\bullet$ Fig. 1 b).
Multiple endoscopic tools were employed to extract or crush the stone, including snare, retrieval net, regular and lithotripsy baskets, as well as electrohydraulic lithotripter probe. However, the stone could not be extracted but was reduced in size resulting in disimpaction and further migration downstream. A moderate-sized defect was apparent in the floor of the duodenal bulb confirming a cholecystenteric fistula ( Fig. 1c). An additional 1-cm gallstone was visualized within the lumen of the gallbladder ( $\bullet$ Fig. 1d). Although the acute gastric outlet obstruction was relieved, the patient ultimately required repeat laparotomy with an enterotomy for stone extraction ( $\mathbf{F i g}$. 1 e). He recovered well postoperatively.
These findings suggest gallstone ileus with gastric outlet obstruction known as Bouveret's syndrome. Gallstone ileus is an unusual cause of small-bowel obstruction and usually results in impaction of a large stone within the terminal ileum [1]. However, a large biliary calculus can become dislodged in the proximal duodenum after exiting the gallbladder through a cholecystenteric fistula. This results in a mechanical gastric outlet obstruction $[2,3]$. Endoscopic therapy to remove or crush the stone is a challenging task and often requires definitive surgical intervention with stone removal, cholecystectomy, and possible repair of the fistula [4].

Competing interests: None 
Endoscopy_UCTN_Code_CCL_1AB_2AZ_3AZ

\section{P. Srungaram, J. Sreenarasimhaiah} Division of Digestive and Liver Diseases, University of Texas Southwestern Medical Center, Dallas, Texas USA

\section{References}

1 Reisner RM, Cohen JR. Gallstone ileus: a review of 1001 reported cases. Am Surg 1994; 60: $441-446$

2 Lowe AS, Stephenson S, Kay CL, May J. Duodenal obstruction by gallstones (Bouveret's syndrome): a review of the literature. Endoscopy 2005; 37: $82-87$

3 Doycheva I, Limaye A, Suman A et al. Bouveret's syndrome: case report and review of the literature. Gastroenterol Res Pract, Published online 2009 April 7; DOI: 10.1155/ 2009/914951

4 Malvaux P, Degolla R, De Saint-Hubert $M$ et al. Laparoscopic treatment of a gastric outlet obstruction caused by a gallstone (Bouveret's syndrome). Surg Endosc 2002; 16: $1108-1109$

\section{Bibliography}

DOI $10.1055 / \mathrm{s}-0030-1255718$

Endoscopy 2010; 42: E215-E216

(c) Georg Thieme Verlag KG Stuttgart - New York . ISSN 0013-726X

\section{Corresponding author}

\section{J. Sreenarasimhaiah, MD}

Division of Digestive and Liver Diseases

University of Texas Southwestern Medical Center 5323 Harry Hines Blvd, MC 9083

Dallas

Texas

USA 75390

Fax: +1-214-645-0596

Jayaprakash.Sreenarasimhaiah@

UTSouthwestern.edu 